\title{
Family Madicineand
community Heath Study of type 2 diabetes management among patients in a Macau primary care setting
}

\author{
In Wong
}

To cite: Wong I. Study of type 2 diabetes management among patients in a Macau primary care setting. Fam Med Com Health 2019;7:e000031. doi:10.1136/fmch-2018-000031

Received 26 September 2018 Revised 12 August 2019 Accepted 18 August 2019
Check for updates

(c) Author(s) (or their employer(s)) 2019. Re-use permitted under CC BY-NC. No commercial re-use. See rights and permissions. Published by BMJ.

Health Bureau, Macau SAR Government, Macau, China

Correspondence to Dr In Wong; michelle.wongin@gmail.com

\begin{abstract}
Background In the primary care setting in Macau, type 2 diabetes mellitus (T2DM) is the seventh most common reason for consultation. Inadequate glycaemic control constitutes a major public health problem and is associated with premature death and disability and decreased quality of life. Moreover, this condition substantially increases healthcare expenditures. Objective The primary objective was to assess the successful glycaemic control rates, blood pressure (BP) and cholesterol control rates in patients with T2DM in a Macau primary care setting. The secondary objective of this study was to assess the delay of insulin initiation in the Sao Lourence Health Center.
\end{abstract}

Methods Patients were stratified according to age $(<65$ years vs $\geq 65$ years) and sex. Successful glycaemic control was defined as glycated haemoglobin $(\mathrm{HbA} 1 \mathrm{c})<7 \%$. Successful cholesterol control was defined as a lowdensity lipoprotein cholesterol (LDL-C) level $<2.6 \mathrm{mmol} / \mathrm{L}$, and BP control was defined as BP $<140 / 90 \mathrm{~mm} \mathrm{Hg}$. Results Among the 2157 participants included in this study, 1046 (48.5\%) patients had $\mathrm{HbA1C}<7 \%, 1209$ (56.1\%) patients had BP <140/90 mm Hg and 1244 (57.7\%) patients had LDL-C $<2.6 \mathrm{mmol} / \mathrm{L}$. In conclusion, only $403(18.7 \%)$ patients met the targets for all three measures. Of the 235 patients who were on insulin therapy, the mean $( \pm \mathrm{SD})$ duration from T2DM diagnosis to insulin initiation was $7.47 \pm 6.52$ years, the mean $( \pm S D)$ duration from $\mathrm{HbA} 1 \mathrm{c}$ not meeting the target $(\mathrm{HbA} 1 \mathrm{c} \geq 7 \%$ over 1 year and persistently) to insulin initiation was $3.34 \pm 3.66$ years and the mean baseline $\mathrm{HbA} 1 \mathrm{c}$ was $9.13 \%$. Compared with patients with a longer duration ( $\geq 5$ years) of $\mathrm{HbA} 1 \mathrm{c}$ not meeting the target before insulin initiation, those who started insulin within 1 year of $\mathrm{HbA1c}$ not meeting the target had a better glycaemic control rate (40.7\% vs $13 \%)$.

Conclusions Nearly half of the patients at Sao Lourence Health Center, a primary care centre in Macau, met the glycaemic control target, but less than one-fifth of patients met all three targets for T2DM control. Moreover, there was a delay in insulin initiation for people with T2DM.

\section{INTRODUCTION}

After more than 30 years of development, the primary healthcare network in Macau has been rated as a model by the WHO. ${ }^{1}$ The Macau primary healthcare system mainly comprises eight health centres that provide free medical services to all Macau residents, especially for the management of chronic diseases. All Macau residents can select a family doctor to manage their chronic disease at the health centre in their area of residence. Patients are followed regularly at the health centre as needed, and most essential medicines and laboratory exams are available free of charge at the health centre. In addition, the electronic medical record system has been fully used in Macau health bureau since 2003, and all medication records and test results are automatically recorded in the system database. Type 2 diabetes mellitus (T2DM) is the seventh most common reason for consultation in the primary care setting in Macau. ${ }^{2}$ For the diagnosis and treatment of diabetes, the Macau Health Bureau has developed internal work guidelines based on the guidelines of the American Diabetes Association (ADA) and in light of the actual situation in Macau.

Inadequate control among individuals with diabetes constitutes a major public health problem and is associated with premature death and disability and decreased quality of life. Additionally, this condition substantially increases healthcare expenditures. A timely and aggressive blood glucose-lowering intervention remains the major therapeutic objective for the prevention of microvascular and macrovascular complications arising from diabetes. ${ }^{3}$

Although Macau has a comprehensive healthcare system, no objective data have been previously reported. Therefore, the present study can provide data about the glycaemic control, blood pressure (BP) and cholesterol control rates in patients with T2DM in a Macau primary care setting for academic exchange and future improvement measures and to fill the current gap in research.

In the past few decades, numerous oral hypoglycaemic agents (OHAs) are available 
for the management of diabetes. Life modification along with metformin as the 'step 1' management is generally well accepted and, in fact, it is common clinical experience that some patients never satisfactorily respond to this management. This is the time at which an aggressive 'add on' treatment has to be initiated, and the simplest option is addition of a second oral agent. ${ }^{45}$ This addition will likely reduce glycated haemoglobin (HbA1c) to $<7 \%$ in some patients, but the durability is questionable. ${ }^{67}$ Timely initiation of insulin therapy can reverses glucotoxicity and helps preserve $\beta$-cell function. ${ }^{8}$ To reduce the risk of long-term microvascular and macrovascular complications, the ADA and the European Association for the Study of Diabetes guidelines recommend early adoption of insulin as part of stepwise treatment intensification to lower the HbA1c below a general target of $7 \% .^{45}$

Despite the known benefits of timely insulin initiation, insulin initiation is often delayed, however, particularly in primary care ${ }^{10-12}$ The aims of this study were to assess the successful glycaemic control rate as well as the BP and cholesterol control rates in patients with T2DM at the Sao Lourence Health Center. Moreover, timely insulin initiation among patients with T2DM in a Macau primary care setting was investigated.

\section{METHODS}

\section{Study design}

This study was completed using the computerised clinical records of the Macau Health Bureau from 1 January 2017 to 31 December 2017. All patients with a diagnosis of T2DM in the Sao Lourence Health Center, one of eight health centres in the Macau Health Bureau, were included in this study. The Sao Lourence Health Center is located southeast of the Macau Peninsula. Nearly one-tenth of the population of Macau lives in this area. As of 2017, the number of registered patients at this centre was 52819 . Patient demographics, physical measures, HbA1c level, lipid profile and concomitant medications were extracted by reviewing computerised clinical records.

The inclusion criteria were as follows: (1) the patient had an International Classification of Primary Care - 2nd edition (ICPC2) code of T90 (diabetes and non-insulin dependent) or had the word string 'DM' in the summary of the computerised clinical record, irrespective of sex; (2) the patient's age was $\geq 18$ years; and (3) the patient was followed for diabetes at the Sao Lourence Health Center, as determined by the use of antidiabetes medication or the presence of a HbAlc test ordered by a physician who worked at the Sao Lourence Health Center. Patients with gestational diabetes mellitus or those whose diabetes was followed by endocrinologists of the Centro Hospitalar Conde de Sao Januario or other hospitals were excluded.

A stratified sampling survey was applied during grouping according to: ( 1$)$ age $(<65$ years vs $\geq 65$ years) and (2) sex (male vs female). Assessments of glycaemic, cholesterol and BP control were based on the last record in 2017 reported in the computerised clinical record.
Successful glycaemic control was defined as HbA1c $<7 \%$, and cholesterol control was defined as low-density lipoprotein cholesterol (LDL-C) $<2.6 \mathrm{mmol} / \mathrm{L}$. BP was measured in the clinic with the participant sitting for at least $15 \mathrm{~min}$, and $\mathrm{BP}<140 / 90 \mathrm{~mm} \mathrm{Hg}$ was defined as successful BP control. ${ }^{4}$ Poor glycaemic control was defined as HbAlc $>8 \%$.

Four antidiabetic therapeutic regimens were defined for this study as follows: diet, insulin monotherapy, OHAs (monotherapy or in combination) and OHAs plus insulin.

Subsequently, the success of glycaemic control in patients on insulin therapy (monotherapy or in combination) was assessed. The patients were grouped according to the duration of T2DM, time of insulin initiation (from T2DM diagnosis to the time of insulin initiation) and duration of HbAlc not meeting the target (HbAlc $\geq 7 \%$ over 1 year and persisting until the time of insulin initiation).

In patients whose $\mathrm{HbAlc}$ was $\geq 8 \%$ and who were not on insulin therapy, disease duration and duration of HbAlc not meeting the target (HbAlc $\geq 7 \%$ over 1year and persisting to the present) were reviewed to assess the delay of insulin initiation regarding the treatment of their condition.

\section{Statistical analysis}

The analyses were based on patients enrolled in the study. All recorded data were descriptively analysed. The Pearson's $\chi^{2}$ and t-tests were used to compare qualitative and continuous variables, respectively. All statistical test were carried out at a significance level of $5 \%$.

All data analyses were using SPSS V.24.

\section{Ethical issues}

The patients' identities were protected, and no individual patients could be identified from the data. The patients and doctors involved encountered no harm because this was an audit of patients with T2DM.

\section{RESULTS}

\section{Overall study population}

A total of 2157 patients were included in the study. The general characteristics of the study population according to sex are summarised in table 1 . The mean $( \pm \mathrm{SD})$ age was $64.78 \pm 11.36$ years, and $49.7 \%$ of the patients were male. From 1 January 2017 to 31 December 2017, of the 2157 subjects, $1930(89.5 \%)$ patients had at least one HbAlc record, $2149(99.6 \%)$ patients had at least one BP record and $1943(90.1 \%)$ patients had at least one LDL-C record. The mean HbAlc level was $7.12 \% \pm 1.22 \%$, and $1046(48.5 \%)$ patients had an HbAlc level lower than $7 \%$. BP readings were lower than $140 / 90 \mathrm{~mm} \mathrm{Hg}$ in $1209(56.1 \%)$ patients, and $1244(57.7 \%)$ patients had LDL-C levels lower than $2.6 \mathrm{mmol} / \mathrm{L}$. Ultimately, only 403 $(18.7 \%)$ patients met the targets for all three measures.

There were no significant differences in glycaemic control based on the proportion of $\mathrm{HbA1c}<7 \%$, BP 
Table 1 General characteristics of the study population according to sex

\begin{tabular}{|llccc}
\hline Characteristic & $\begin{array}{l}\text { Overall } \\
(\mathbf{n = 2 1 5 7 )}\end{array}$ & $\begin{array}{l}\text { Male } \\
(\mathbf{n = 1 0 7 3 )}\end{array}$ & $\begin{array}{l}\text { Female } \\
(\mathbf{n}=\mathbf{1 0 8 4})\end{array}$ & P value \\
\hline Age, years & $64.78 \pm 11.36$ & $63.53 \pm 10.96$ & $66.03 \pm 11.62$ & $<0.0001$ \\
\hline HbA1c $<7 \%, \%$ & 48.5 & 48.3 & 48.7 & 0.874 \\
\hline Mean HbA1c, \% & $7.12 \pm 1.22$ & $7.16 \pm 1.28$ & $7.09 \pm 1.16$ & 0.254 \\
\hline BP $<140 / 90$ mm Hg,\% & 56.1 & 55.5 & 56.6 & 0.578 \\
\hline Mean SBP, mm Hg & $137.46 \pm 17.99$ & $136.98 \pm 17.83$ & $137.93 \pm 18.15$ & 0.219 \\
\hline SBP <140 mm Hg, \% & 57.6 & 57.8 & 57.5 & 0.884 \\
\hline Mean DBP, mm Hg & $76.13 \pm 11.28$ & $78.20 \pm 11.26$ & $74.09 \pm 10.93$ & $<0.0001$ \\
\hline DBP <90 mm Hg, \% & 88.2 & 84.4 & 92.0 & $<0.0001$ \\
\hline LDL-C <2.6 mmol/L, \% & 57.7 & 59.1 & 56.3 & 0.186 \\
\hline Mean LDL-C, mmol/L & $2.38 \pm 0.88$ & $2.47 \pm 0.87$ & $2.27 \pm 0.88$ & 0.051 \\
\hline Meet triple targets, \% & 18.7 & 18.7 & 18.6 & 0.954 \\
\hline
\end{tabular}

BP, blood pressure; DBP, diastolic blood pressure; HbA1c, glycated haemoglobin; LDL-C, low-density lipoprotein cholesterol; SBP, systolic blood pressure.

control and LDL-C control by sex (table 1). Compared with younger patients, older patients had better control of LDL-C $(61.7 \%$ vs $53.9 \%$; $\mathrm{p}<0.0001)$ but poorer control of BP $(51.3 \%$ vs $60.4 \%$; $\mathrm{p}<0.0001)$. There was no significant difference in glycaemic control (table 2).

\section{Pharmacological treatment}

Four antidiabetic therapeutic regimens were defined for this study. Of the 2157 participants, 416 (19.3\%) patients were on diet control only, $17(0.8 \%)$ patients were on insulin monotherapy, $1506(69.8 \%)$ patients were on OHAs only and $218(10.1 \%)$ patients were on OHAs plus insulin (figure 1).

Of the 1506 patients who were on OHA therapy, 1066 (70.8\%) patients were on metformin, and 863 (57.3\%) patients were on one kind of OHA while other on combination therapy.
Of the 235 patients who were on insulin therapy, the most commonly prescribed insulin was insulin glargine in $89.8 \%$ of patients, followed by Protaphane in $8.1 \%$ and Mixtard in $1.7 \%$ (figure 2). The mean T2DM duration in this study population was $10.93 \pm 7.31$ years, the mean duration from T2DM diagnosis to insulin initiation was $7.47 \pm 6.52$ years and the mean duration from HbAlc not meeting the target (HbAlc $\geq 7 \%$ persistently) to insulin initiation was $3.34 \pm 3.66$ years. The mean baseline HbA1c was $9.13 \%$.

The successful glycaemic control rate $(\mathrm{HbA1c}<7 \%)$ was $62.5 \%$ in patients with a T2DM duration of less than 1 year, but the successful glycaemic control rate decreased to $31.4 \%, 27.1 \%$ and $15.3 \%$ in patients with T2DM durations of 1-4 years, 5-9 years and longer than 10 years, respectively ( $p=0.003$ ) (figure 3 ). Moreover, the successful

Table 2 General characteristics of the study population according to age

\begin{tabular}{|lcccc}
\hline Characteristic & $\begin{array}{l}\text { Overall } \\
(\mathbf{n = 2 1 5 7 )}\end{array}$ & $\begin{array}{l}<65 \text { years } \\
(\mathbf{n = 1 1 2 2})\end{array}$ & $\begin{array}{l}\mathbf{6 5} \text { years } \\
(\mathbf{n = 1 0 3 5 )}\end{array}$ & P value \\
\hline Age, years & $64.78 \pm 11.36$ & $56.21 \pm 6.62$ & $74.08 \pm 7.45$ & $<0.0001$ \\
\hline HbA1c $<7 \%, \%$ & 48.5 & 48.1 & 48.9 & 0.724 \\
\hline Mean HbA1c, \% & $7.12 \pm 1.22$ & $7.19 \pm 1.24$ & $7.05 \pm 1.20$ & 0.01 \\
\hline BP $<140 / 90 \mathrm{~mm} \mathrm{Hg}, \%$ & 56.1 & 60.4 & 51.3 & $<0.0001$ \\
\hline Mean SBP, mm Hg & $137.46 \pm 17.99$ & $135.16 \pm 16.86$ & $139.95 \pm 18.83$ & $<0.0001$ \\
\hline SBP <140 mm Hg, \% & 57.6 & 62.7 & 52.1 & $<0.0001$ \\
\hline Mean DBP, mm Hg & $76.13 \pm 11.28$ & $78.98 \pm 10.76$ & $73.05 \pm 11.03$ & $<0.0001$ \\
\hline DBP $<90 \mathrm{~mm} \mathrm{Hg}, \%$ & 88.2 & 83.9 & 92.9 & $<0.0001$ \\
\hline LDL-C <2.6 mmol/L, \% & 57.7 & 53.9 & 61.7 & $<0.0001$ \\
\hline Mean LDL-C, mmol/L & $2.38 \pm 0.88$ & $2.34 \pm 0.87$ & $2.42 \pm 0.90$ & $<0.0001$ \\
\hline Meet triple targets, \% & 18.7 & 19.6 & 17.7 & 0.251 \\
\hline
\end{tabular}

BP, blood pressure; DBP, diastolic blood pressure; HbA1c, glycated haemoglobin; LDL-C, low-density lipoprotein cholesterol; SBP, systolic blood pressure. 


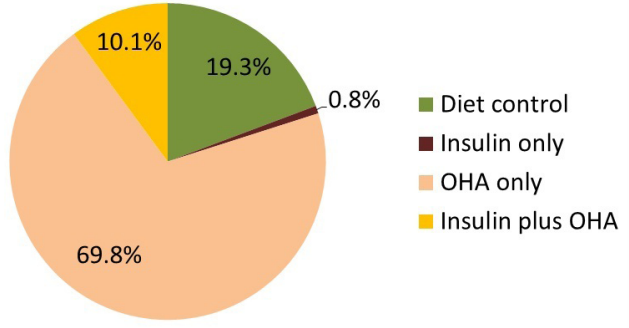

Figure 1 Proportion of antidiabetic therapeutic regimens. $\mathrm{OHA}$, oral hypoglycaemic agent.

glycaemic control rate decreased gradually from $45.5 \%$ to $14.7 \%$ with a longer period of time between the T2DM diagnosis and insulin initiation $(\mathrm{p}=0.001)$ (figure 4). Compared with patients with a longer duration ( $\geq 5$ years) of HbA1c not meeting the target before insulin initiation, patients who started insulin within 1 year of HbA1c not meeting the target had a better glycaemic control rate ( $40.7 \%$ vs $13 \%, \mathrm{p}<0.0001$ ) (figure 5 ).

Of the 2157 patients, 209 (9.7\%) had an HbAlc level $\geq 8 \%$ and were not on insulin therapy. Of this study population with poor glycaemic control, the mean age was $64.36 \pm 11.07$ years, the mean $\mathrm{HbA1c}$ was $9.01 \% \pm 1.28 \%$, the mean T2DM duration was $9.31 \pm 5.8$ years and the mean duration of persistent HbA1c $\geq 8 \%$ was $2.19 \pm 3.23$ years. Meanwhile, $92.3 \%$ of the poor glycaemic control patients already on two or more kinds of OHAs before their HbAls not meeting target, the mean duration between initiation of two kinds of OHAs to HbA1c $\geq 8 \%$ was $4.23 \pm 4.2$ years.

\section{DISCUSSION}

\section{Main findings}

In this first study of patients with T2DM in the Sao Lourence Health Center, even if patients with diabetes received free medical services, only $48.5 \%$ of patients with T2DM in the Sao Lourence Health Center met the glycaemic control target of HbAlc $<7 \%$. The rate of successful glycaemic control in our study was higher than that in China, ${ }^{13}$ Thailand $^{14}$ and Singapore,${ }^{15}{ }^{16}$ ranging

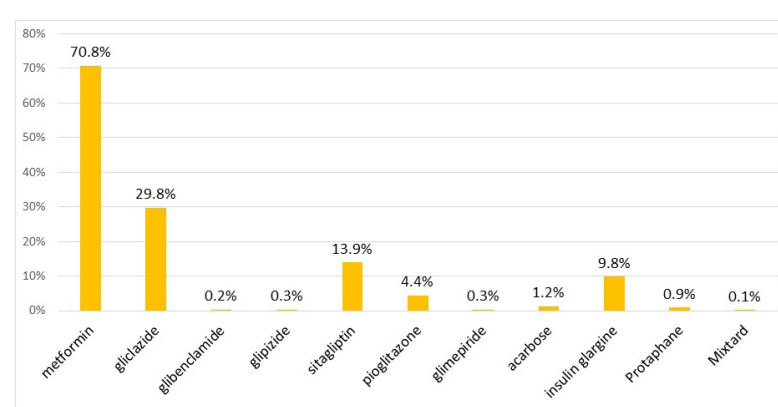

Figure 2 Proportion of OHAs and insulin use in the Sao Lourence Health Center. OHA, oral hypoglycaemic agent.

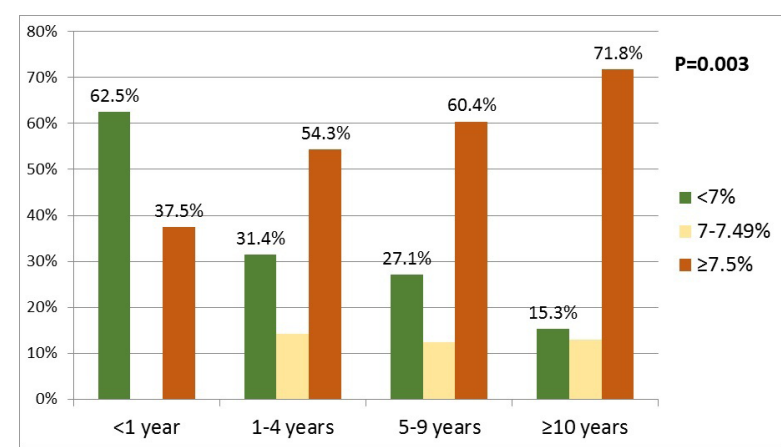

Figure 3 Glycaemic control rate in patient on insulin therapy based on T2DM duration. T2DM, type 2 diabetes mellitus.

from $19 \%$ to $29 \%$. Except for Macau, diabetes treatment in other countries or regions is subject to a fee; thus, the free services in the primary care setting may improve the successful glycaemic control rate of patients with diabetes. We have also demonstrated that younger individuals were associated with poorer glycaemic control (table 2), and this finding is similar to the study in Malaysia ${ }^{17}$ and France. ${ }^{18}$ Why glycaemic control might be poorer in younger individuals is unclear, but some evidence have suggested that younger patients may face more hurdles to regular physical activity and healthy diet, whereas older individuals may have more frequently access to medical care, more motivated to manage their medical conditions and more compliant with medication. ${ }^{1718}$

Compared with the rates of successful control of blood glucose, BP or LDL-C, which were close to $50 \%$, the proportion of patients who met the requirements of successful control for all three measures was only $18.5 \%$. Similar conditions have been reported in China. ${ }^{13}$ In theory, hypertension and LDL-C treatments are easier to use and more effective than hypoglycaemic agents, but a large proportion of people with diabetes fail to meet the targets for BP and LDL-C. This phenomenon indicates that physicians do not perform a comprehensive assessment of the risk factors for patients with diabetes and do not emphasise this information to patients. Therefore, it is necessary to strengthen physician training on this topic and to strengthen patient awareness.

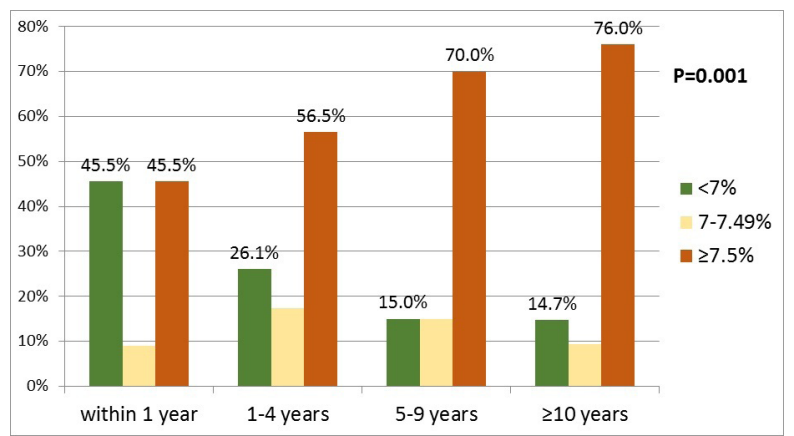

Figure 4 Glycaemic control rate based on duration from T2DM diagnosis to insulin initiation. T2DM, type 2 diabetes mellitus. 


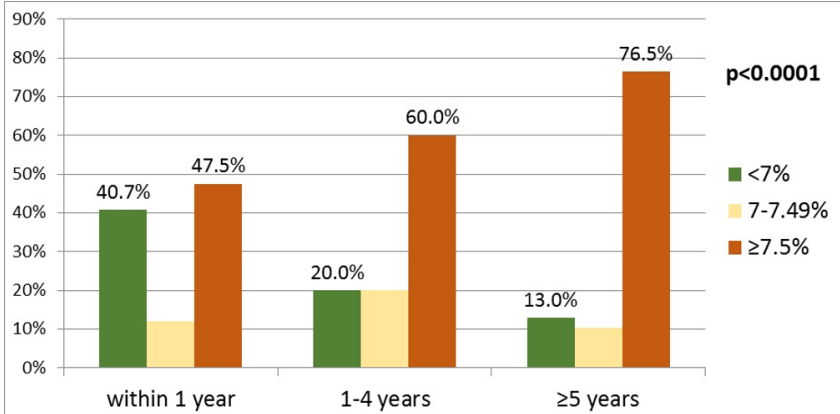

Figure 5 Glycaemic control rate based on duration from $\mathrm{HbA1c} \geq 7 \%$ persistently to time of insulin initiation. $\mathrm{HbA1c}$, glycated haemoglobin.

Considering that the $\mathrm{BP}$ control rate was calculated based on BP measured in the clinic and that many patients will have higher BP in the clinic, an underestimation of $\mathrm{BP}$ control could not be excluded. According to prior (2017) audit results of cholesterol management in the Sao Lourence Health Center, some physicians did not focus on aggressive lipid-lowering treatment for patients at high risk, perhaps because of limited knowledge about risk assessment for cardiovascular disease. ${ }^{19}$ In the past, some studies have analysed the relationships among BP, cholesterol and glycaemic control. The conclusion is that HbAlc is inversely related to BP and cholesterol levels. ${ }^{145}$ However, in fact, the behavioural patterns of patients and doctors in the treatment of diabetes are the most fundamental factors.

The secondary objective of this study was to assess the delay of insulin initiation at the Sao Lourence Health Center. The result showed that most patients were on OHAs only and that most physicians preferred to initiate insulin when the patient failed to meet glycaemic control with two or more OHAs. Moreover, the successful glycaemic control rate was inversely related to T2DM duration, the time between the T2DM diagnosis and insulin initiation and the duration of poor glycaemic control.

Delay of insulin initiation is a worldwide problem in the management of T2DM. Despite the benefits of timely insulin initiation, the basal insulin initiation is often delay in patients with diabetes. ${ }^{10-12}$ In the 11-country First Basal Insulin Evaluation (FINE)-Asia study, mean duration of diabetes was 9.3 years and baseline HbAlc was $9.8 \% .{ }^{20}$ Baseline HbA1c was highest in patients from Southeast Asia (defined as Bangladesh, Hong Kong, Indonesia, Singapore and Vietnam; mean HbAlc $=10.5 \%$ ), followed by Thailand and Taiwan (mean HbAlc $=10.2 \%$ for both) ${ }^{20}$ The reasons underlying this resistance to the initiation of insulin therapy must be understood to begin reversing the trend of delayed insulin initiation. Exploring patients' concerns and beliefs regarding insulin therapy is crucial for formulating effective strategies for timely insulin initiation and assisting physicians in delivering patient-centred care. Several barriers to insulin initiation and intensification exist both for people with T2DM and physicians; the patient-reported barrier include fear of inconvenience and pain of injection. ${ }^{2122}$ The physicians' barriers include low motivation, lack of familiarity or experience with treatments and time constraints. ${ }^{22}{ }^{23}$ By 2000, at least six new products in four new classes of OHAs were available; the introduction of these products may also be a reason physicians delay insulin initiation.

Delay of insulin initiation may cause people being treated with OHAs to experience a high glycaemic burden for extended periods before insulin therapy is initiated. ${ }^{24}$ However, the aim of this study was not to analyse whether any of these factors were associated with poor attainment of target levels. Additional studies will be needed to evaluate which factors influence these outcomes.

\section{Strengths and limitations of the study}

One of the limitations of this study was the inability to determine the degree to which these factors played a role in physician decision making. Another limitation was that only a small number of family doctors and only one health centre in Macau participated in this study. Selection bias cannot be excluded because the participating physicians likely had an increased interest in T2DM management and may not be fully representative of the broader primary care physician population in Macau. A strength of this study is that all cases identified had routine electronic medical records available, providing a unique perspective on the Macau primary care setting.

\section{CONCLUSIONS}

The current study shows that nearly half of the patients in the Sao Lourence Health Center met the glycaemic control target but that less than one-fifth of patients met all three measures of T2DM control. When poor control is present, delayed insulin initiation results in poorer glycaemic control. Therefore, further research should be extended to all health centres to assess the T2DM management throughout the Macau primary care setting, and more education regarding the exact details of insulin therapy is required for both clinicians and patients.

\section{Key points}

Assessing the control rate of type 2 diabetes and the delay of insulin initiation in a Macau primary care setting.

- Even if patients with diabetes receive free medical services, only approximately $20 \%$ of patients achieve full control, and the delay of insulin initiation is an important factor.

- This research reflected the need for improvements in type 2 diabetes management in the Macau primary care setting. Further feedback programme based on this research will be conducted for continuous quality improvement. 
Acknowledgements I acknowledge the support provided by the director of the Sao Lourence Health Center and the general practitioners who participated in my research.

Funding The authors have not declared a specific grant for this research from any funding agency in the public, commercial or not-for-profit sectors.

Competing interests None declared.

Patient consent for publication Not required.

Provenance and peer review Not commissioned; externally peer reviewed.

Data availability statement Data may be obtained from a third party and are not publicly available.

Open access This is an open access article distributed in accordance with the Creative Commons Attribution Non Commercial (CC BY-NC 4.0) license, which permits others to distribute, remix, adapt, build upon this work non-commercially, and license their derivative works on different terms, provided the original work is properly cited, appropriate credit is given, any changes made indicated, and the use is non-commercial. See: http://creativecommons.org/licenses/by-nc/4.0/.

\section{REFERENCES}

1. Breve história de desenvolvimento DOS Serviços de Saúde. Available: https://www.ssm.gov.mo/Portal/portal.aspx?lang=pt

2. de Saúde S, da Região G. Administrativa especial de Macau. Boletim estatístico, 2016. Available: https://www.ssm.gov.mo/statistic/2016/ index.html

3. Selvin E, Marinopoulos S, Berkenblit G, et al. Meta-analysis: glycosylated hemoglobin and cardiovascular disease in diabetes mellitus. Ann Intern Med 2004;141:421-31.

4. Diabetes Association's Standards of Medical Care in Diabetes-2018. Diabetes Care 2018;41(Suppl 1):S1-S159.

5. Davies MJ, D'Alessio DA, Fradkin J, et al. Management of hyperglycemia in type 2 diabetes, 2018. A consensus report by the American diabetes association (ADA) and the European association for the study of diabetes (EASD). Diabetes Care 2018;41:2669-701.

6. Kahn SE, Haffner SM, Heise MA, et al. Glycemic durability of rosiglitazone, metformin, or glyburide monotherapy. $N$ Engl J Med 2006;355:2427-43.

7. Maedler K, Carr RD, Bosco D, et al. Sulfonylurea induced betacell apoptosis in cultured human islets. J Clin Endocrinol Metab 2005;90:501-6.

8. Gleason CE, Gonzalez M, Harmon JS, et al. Determinants of glucose toxicity and its reversibility in the pancreatic islet beta-cell line, HIT-T15. Am J Physiol Endocrinol Metab 2000;279:E997-E1002.

9. Poitout V, Robertson RP. Glucolipotoxicity: fuel excess and beta-cell dysfunction. Endocr Rev 2008;29:351-66.
10. Goodall G, Sarpong EM, Hayes C, et al. The consequences of delaying insulin initiation in UK type 2 diabetes patients failing oral hyperglycaemic agents: a modelling study. BMC Endocr Disord 2009;9:19.

11. Calvert MJ, McManus RJ, Freemantle N. The management of people with type 2 diabetes with hypoglycaemic agents in primary care: retrospective cohort study. Fam Pract 2007;24:224-9.

12. Calvert MJ, McManus RJ, Freemantle N. Management of type 2 diabetes with multiple oral hypoglycaemic agents or insulin in primary care: retrospective cohort study. $\mathrm{Br} J$ Gen Pract 2007;57:455-60.

13. Chen R, Ji L, Chen L, et al. Glycemic control rate of T2DM outpatients in China: a multi-center survey. Med Sci Monit 2015;21:1440-6.

14. Kosachunhanun N, Benjasuratwong Y, Mongkolsomlit S, et al. Thailand diabetes registry project: glycemic control in Thai type 2 diabetes and its relation to hypoglycemic agent usage. J Med Assoc Thai 2006;89 Suppl 1:S66-71.

15. Sabanayagam C, Shankar A, Saw SM, et al. Prevalence of diabetes mellitus, glycemic control, and associated factors in a Malay population in Singapore. Asia Pac J Public Health 2009;21:385-98.

16. Brath $\mathrm{H}$, Paldánius $\mathrm{PM}$, Bader $\mathrm{G}$, et al. Differences in glycemic control across world regions: a post-hoc analysis in patients with type 2 diabetes mellitus on dual antidiabetes drug therapy. Nutr Diabetes 2016;6:e217.

17. Ahmad NS, Ramli A, Islahudin F, et al. Medication adherence in patients with type 2 diabetes mellitus treated at primary health clinics in Malaysia. Patient Prefer Adherence 2013;7:525-30.

18. Bezie $Y$, Molina M, Hernandez N, et al. Therapeutic compliance: a prospective analysis of various factors involved in the adherence rate in type 2 diabetes. Diabetes Metab 2006;32:611-6.

19. Wong I. A pilot study of cholesterol management among patients in a Macau primary care setting. J Prim Care Gen Pract 2018;1:7-11.

20. Ji L, Tsai S-T, Lin J, et al. National variations in comorbidities, glycosylated hemoglobin reduction, and insulin dosage in Asian patients with type 2 diabetes: the fine-Asia registry. Diabetes Ther 2015;6:519-30.

21. Larkin ME, Capasso VA, Chen C-L, et al. Measuring psychological insulin resistance: barriers to insulin use. Diabetes Educ 2008;34:511-7.

22. Kim SG, Kim NH, Ku BJ, et al. Delay of insulin initiation in patients with type 2 diabetes mellitus inadequately controlled with oral hypoglycemic agents (analysis of patient- and physician-related factors): a prospective observational dipp-factor study in Korea. $J$ Diabetes Investig 2017;8:346-53.

23. Kunt T, Snoek FJ. Barriers to insulin initiation and intensification and how to overcome them. Int J Clin Pract Suppl 2009;(164):6-10.

24. Brown JB, Nichols GA, Perry A. The burden of treatment failure in type 2 diabetes. Diabetes Care 2004;27:1535-40. 